refute it. The events themselves may be influenced by the prevailing political climate. For example, is it unthinkable that Truman's decision to commit troops in Korea was a reflection of the mood prevalent in 1949 and 1950, while Eisenhower's decision not to commit troops in Vietnam was a reflection of the mood prevalent in 1954?

The authors note the relation between events and war moods, but not throughout. They speak of war-weariness growing in the fall of 1944 and the winter of 1945 . However, in the fall the Allies' drive across France petered out and in December there was a serious setback-the Battle of the Bulge. War-weariness disappeared in the spring. It is, of course, well known that war moods change drastically with victories and defeats. This makes the assessment of war-weariness extremely difficult, and it also means that no clean way exists for testing the self-propelled dynamics of the war mood theory.

As long as the theoretical discussion of war moods is kept on the level of qualitative speculation, numerical data are not of much help. They can be interpreted in many ways and so can be cited to support even contradictory assumptions. This is especially so when one brings in "covert" moods, which are unobservable in principle. A theory of war moods would be pushed forward if we could somehow isolate a sequence of events about which data pertinent to the formulated theory could be obtained. I still have no idea how this can be done.

\section{Second Comment}

\section{PHILIP E. CONVERSE}

Survey Research Center, The University of Michigan

The paper by Campbell and Cain raises a number of important issues surrounding the general relation between public opinion and governmental decisions as to the initiation and termination of wars. Stripped to its essentials, the underlying model formalized by Richardson supposes that some level of war-readiness, usually latent, exists in a population; that under certain circumstances this level becomes manifest, rising rapidly by interpersonal "contagion" through a population; and that a sufficient increase in war fever can make some causal contribution to the entrance of the nation into war. Using scattered data from public opinion polls, Campbell and Cain attempt to relate parameters that they estimate for a central Richardson equation to an earlier estimate he had made. One or two fair "fits" are found, along with several misfits. The issues underscored by the paper have to do with Richardson's conception of the problem, the empirical referents which are presumed, and the nature of the data that may be brought to bear in any effort at confirmation.

Taking the relatively technical problems first, one can commiserate with the authors for the inadequacy of the data available for even rough parameter estimation within the terms of the primary Richardson equation used. Part of the problem, as the authors note, has to do with the dearth of identically-worded questions, particularly in the earlier period. The estimation of the Richardson constant might vary widely according to whether the "war fever level" was pegged at 5 percent or 20 percent in the initial reading; yet it is not difficult for the survey researcher to move a response distribution this "distance" by changes in 
the wording of a question-changes so slight as to appear perfectly identical in intent to the lay reader. Many of the warrelevant questions catalogued in this paper are extremely divergent in intent and meaning for the respondent. A question as to the individual's interest in volunteering for military service certainly has a different significance for a 76-year-old arthritic than it does for a 22-year-old who has just been fired from his job. And the mix of response determinants present in such an item must say something different about absolute levels of "war fever" in a population than do responses to more hypothetical choices about national destiny. The authors do make a commendable attempt to avoid the worst heterogeneity in question wording, but the exact proportions finally used for the main exercise in parameter estimation (December 1941) still depend on items of somewhat different wording.

More oppressive still is the problem of the timing of the data collections. Ideally, for the purposes of the Richardson estimates, the pulse-reading should be nearly instantaneous, with the field work occupying no more than a day at most. Yet it would be next to impossible to complete a national sample of any respectability within a day, or-for that matter-within several days. It would take a massive field staff to do a rapid survey; quite apart from that, a good sample also requires that certain individuals predesignated by probability criteria be interviewed without haphazard substitution of others nearby who may be more available. At best, less than half of a predesignated cross-section sample of adults can typically be located and interviewed on the interviewer's first approach. The rest require call-backs and other delays. Hence the investigating agency must either extend the period of the survey or accept a makeshift sample of unknown representativeness, for people who are easily accessible to interviewers can differ in many systematic ways (including attitudes toward war) from those who require extended pursuit.

In point of fact, the crucial data from the 1930s and early 1940s used by Campbell and Cain were collected by methods long since viewed as shoddy and unrepresentative. Even so, the better among these samples were in the field for periods of at least several days, if not a week or more. Naturally, we would not want to be overly precise about an estimate that 15 percent of the population, in "early December" 1941, thought the country "should have been fighting before now" without knowing whether none or ten percent or a quarter of the interviewing was incomplete until after announcement of the attack on Pearl Harbor.

Let us suppose, however, that good samples had indeed been interviewed almost instantaneously on December 1, 1941, and again on December 15, with the lapse of 14 days assumed by the authors. Let us suppose further that the data showed a change in some indicator of war-readiness from the 15 percent to the 86 percent level, exactly as in the case presented. Why should we not imagine that the 15 percent level was maintained until the first news of the Pearl Harbor attack broke upon the American public, and that virtually all of the shift to a level of 86 percent occurred within the 24 or 36 hours that it may have taken for almost all of the population to have heard of the attack? Indeed, this is a more plausible reading of events than that implied by the authors, and is entirely consistent with all of the data presented. Yet if the reaction were complete within two days or less of the first news, then the value of $C$ which results is not within even 
an order of magnitude of the Richardson estimates for World War I.

This would not be at all surprising, and certainly no discredit to Richardson, for it is very doubtful that either the kind of event sequence or the kind of public opinion that he had in mind are represented in most of these data. Here we move from narrow technical concerns to larger conceptual questions. Richardson was concerned with the contagion of a sense of belligerence in a national population that would have some causal influence on governmental decisions about the conduct of war, either in compelling the government to new action or in providing it with a sense of latitude toward such actions. In at least the Pearl Harbor and Korean cases, it is likely that the change in public opinion was a consequence rather than a cause of the outbreak of hostilities. This is a commentary not only on the dubious predictive significance of the data, as the authors observe, but also on the extremely limited appropriateness of the "fever" and "contagion" bases of the Richardson model for such instances.

Perhaps most important conceptually, however, are the ambiguities and contradictions which lie between the definitions of "public opinion" implied by Richardson on the one hand and Campbell and Cain on the other. The empirical referents of "public opinion" are radically different in the two cases. The Campbell-Cain treatment is based on a measurement of public opinion in a head-count or "one man, one vote" sense, with the total adult population as the universe. Even giving Richardson enormous credit as a shrewd observer, his impressions of public opinion certainly had no such basis. His assessment necessarily rested on what was visible as public opinion: published elite commentary, informal discussions at middle-elite parties, the reactions of newspaper editors in central and provincial capitals, some distillation of "letters to the editor" from the supposed grassroots, and perhaps stray soundings with a few taxi-drivers and barbers in major urban centers.

While we do not have much precise knowledge of the interplay between these layers of public opinion, evidence has accumulated that they are scarcely identical, and at times can diverge from one another in astonishing degree. We have found instances, for example, where "vocal" opinion as measured by public letter-writing may suggest a $60-40$ division on an issue, whereas from the same sample treated at the same time in the head-count sense, the same issue showed a 25-75 division, i.e., strongly in the opposite direction.

This is not of course to argue that the two types of opinion are never similar, or never move in similar directions. When a fait accompli drastically restructures the situation in common ways for both "visible" and "invisible" observers-as was roughly true in the Pearl Harbor and Korean cases -the two layers probably move in a common direction at something like the same rate. But this class of cases is not the most heavily populated, and in any event it is the class of cases in which the causal context of the Richardson or Campbell-Cain discussions is least relevant.

If one asks which type of public opinion is likely to have had more causal efficacy in the initiation or termination of wars, the answer for any broad historical sweep of time is self-evident. Prior to the 1930s national leaders could scarcely have been influenced by public opinion in the Campbell-Cain sense, for such opinion was-for almost all intents and purposes-both unknown and unknowable. And since social 
power and influence are very disproportionately concentrated among the contributors to "visible" opinion, some governmental responsiveness to sentiment from these sources would not be implausible.

In the period since the advent of opinion polling, it is of course possible that public opinion in the Campbell-Cain sense has subtly replaced the Richardson variety, with the same dynamics and causal contribution despite the new empirical referent. It is not my impression that this is so, however, and for various reasons.

One reason is that the results of public opinion polls are not always accorded high credibility, and sometimes justifiably so. Secondly, governmental decision-makers are prone to see public opinion in its most "mass" sense as an entity to guide, more than to be guided by. ${ }^{1}$ Finally, it seems true that if such mass opinion measurements are credited at all where policies are at stake, they are at most "weighted in" by leadership with impressions of public opinion formed in the Richardson manner. This means that when the two types of public opinion turn out to be extremely discrepant, governments may simply profit from the latitude provided to act in the di-

\footnotetext{
${ }^{1}$ In this regard, see the statement by Adam Yarmolinsky of the State Department, "Confessions of a Non-User," Public Opinion Quarterly, 1963.
}

rection they would have preferred in the first place.

Such a major discrepancy was played upon in a masterful fashion by De Gaulle in terminating the Algerian war. By the early months of his regime, elite opinion had moved so massively in favor of steppedup military operations in Algeria that any suggestion of negotiation (earlier a subject for debate) had become defined by the climate of visible opinion as tantamount to treason. At the same time, indifference or disgust at the continuation of the war was widespread in mass opinion. De Gaulle, himself a shrewd consumer of opinion poll results, attempted to lead visible opinion toward a less intransigent position by revealing his own interest in negotiation in small steps over many months. When this tactic produced only limited results, he turned to popular referenda to show, among other things, that mass opinion was not up in arms against his intention to "abandon" Algeria.

Despite all these considerations, I feel that such efforts as that of Campbell and Cain are to be commended-not because they are right, but because the attempt to force complex events into relatively austere and precise models stimulates us to a clarification of definitions and to a new concern over the nature of data collections that would be more appropriate to the spirit of the model, or the model in some more complex form. 